The bul $k$ hi gh- Tc super conduct i ng f I uxgat enet er for nondest ruct i veeval uat i on

\begin{tabular}{|l|l|}
\hline 著者 & $\begin{array}{l}\text { M YAZAK M chi taka, NAKANE H deaki, ADACH } \\
\text { H r oshi }\end{array}$ \\
\hline $\begin{array}{l}\text { j our nal or } \\
\text { publ i cat i on t i t l e }\end{array}$ & I EEE transact i ons on appl i ed super conduct i vi ty \\
\hline vol une & 9 \\
\hline number & 2 \\
\hline page r ange & $3479-3482$ \\
\hline year & $1999-06$ \\
\hline URL & ht t p: //hdl . handl e. net /10258/204 \\
\hline
\end{tabular}


The bul $k$ hi gh- Tc super conduct i ng f I uxgat enet er for nondest ruct i veeval uat i on

\begin{tabular}{|l|l|}
\hline 著者 & $\begin{array}{l}\text { M YAZAK M chi taka, NAKANE H deaki, ADACH } \\
\text { H r oshi }\end{array}$ \\
\hline $\begin{array}{l}\text { j our nal or } \\
\text { publ i cat i on t i t l e }\end{array}$ & I EEE transact i ons on appl i ed super conduct i vi ty \\
\hline vol une & 9 \\
\hline number & 2 \\
\hline page r ange & $3479-3482$ \\
\hline year & $1999-06$ \\
\hline URL & ht t p: //hdl . handl e. net /10258/204 \\
\hline
\end{tabular}




\title{
The Bulk High-Tc Superconducting Fluxgatemeter for Nondestructive Evaluation
}

\author{
Michitaka MIYAZAKI, Hideaki NAKANE and Hiroshi ADACHI \\ Department of Electrical and Electronic Engineering, Muroran Institute of Technology, Muroran, Japan
}

\begin{abstract}
A high-Tc superconductive fluxgate magnetic sensor utilizing sintered $\mathrm{YBa}_{2} \mathrm{Cu}_{3} \mathrm{O}_{7 \cdot \mathrm{x}}$ core is constructed and applied to detect $a$ flaw in an aluminum plate. The magnetic sensor successfully works in an unshielded environment. An electric current was supplied to an aluminum plate directly. A slit $(0.2 \mathrm{~mm}$ width, 30 mm length), which is considered as a flaw, on an aluminum plate is successfully detected with this sensor, even though the slit is covered with another aluminum plate. The sensor can detect the flaw with its direction perpendicular to the electric current in the sample. It's supposed that the sensor can determine the length of the flaw larger than the diameter of the detection coil. These results suggest that the sensor has a potential for nondestructive evaluation of non-magnetic metals such as aluminum alloys, and also for their multi-layered structures.
\end{abstract}

\section{INTRODUCTION}

A bulk high- $\mathrm{T}_{\mathrm{c}}$ superconducting fluxgate magnetic sensor has been investigated by many workers since the discovery of high-Tc superconducting material. A high-Tc superconductive fluxgate magnetic sensor has remarkable features of a high sensitivity, easy operation and easy fabrication. The fundamental properties of the sensor have been reported [1], [2].

Magnetic sensors with a high sensitivity have a potential for the nondestructive evaluation (N.D.E.) of electrically conductive and non-magnetic materials, such as aluminum alloys, titanium and non-magnetic stainless steel. TABLE I shows the comparison of N.D.E. techniques. N.D.E. utilizing the magnetic field is non-contact to the sample in nature. Therefore, it can also be applied to a multi-layered structure with a mechanically soft layer, for which it is difficult to use an ultrasonic method. In addition, in the case of a multi layered sample, internal corrosion disturbs the detection of the flaws.

A SQUID is a most sensitive magnetic sensor. However, if the SQUID is to be used with maximum sensitivity, a magnetic shield is essentially required for its operation, since the environmental magnetic field is strong enough to disturb the SQUID operation. The magnetic shield restricts the size of the sample to be investigated. For example, it's difficult to use

Manuscript received September 14, 1998.
TABLE I

The comparison of non-destructive evaluation techniques.

\begin{tabular}{|c|c|c|c|}
\hline & Ultrasonic N.D.E. & SQUID N.D.E. & $\begin{array}{l}\text { Superconductive } \\
\text { fluxgate N.D.E. }\end{array}$ \\
\hline Gap to sample & Contact & Noncontact & Noncontact \\
\hline $\begin{array}{l}\text { Multi-layered } \\
\text { sample }\end{array}$ & Difficult & Possible & Possible \\
\hline Field operation & Easy & Difficult & Easy \\
\hline
\end{tabular}

for detecting flaws or defects in an aluminum-alloy based structure of an aircraft for the present. Therefore, when the SQUID is operated in magnetically unshielded environments, the sensitivity is usually lower. C. Carr et al. reported the experimental result of N.D.E. utilizing HTS (High Temperature Superconductor) SQUIDs in an unshielded environments [3]. They adopted the electronic gradiometer to reduce the environmental noise. The measured results show that the actual magnitude of the detected magnetic field is approximately a few nanotesla or a few tenths of nanotesla.

On the other hand, Meir Gershenson reported a HTS fluxgate magnetometer which has noise level of $0.17 \mathrm{nT}$ [4]. $H$. Niculescu et al. reported that it has a sensitivity of several tenths of a picotesla [5]. The sensitivity is hardly different from the HTS SQUIDs which are used in an unshielded environments. A superconductive fluxgate magnetic sensor is stably operated without magnetic shield [6]. Therefore an inexpensive and stable N.D.E. system with a superconductive fluxgate magnetic sensor is expected.

In this paper, a new application of a high- $T_{c}$ superconductive fluxgate magnetic sensor for N.D.E. of multi-layered structure aluminum alloy plates is reported.

\section{SENSOR STRUCTURE}

Fig. 1 shows the structure of the superconductive fluxgate magnetic sensor that we used. The fundamental structure of the superconductive fluxgate magnetic sensor is almost the same as a conventional fluxgate sensor except for the core material. The sensor consists of two cores, a modulation coil and two detection coils. In this experiment, two cylindrical pieces of sintered $\mathrm{YBa}_{2} \mathrm{Cu}_{3} \mathrm{O}_{7-x}(\mathrm{YBCO})$ are adopted for the core material, instead of the high permeability material for an 
ordinary fluxgate magnetic sensor. Tc (Superconducting critical temperature) of the core material is $93 \mathrm{~K}$. The cylinder , has a diameter of $12 \mathrm{~mm}$ and a length of $6 \mathrm{~mm}$. The modulation coil and the detection coil are made of an insulator coated copper wire which has the diameter of $0.2 \mathrm{~mm}$. The modulation coil is wound around the cylindrical pieces of sintered YBCO, and the detection coil is wound over the modulation coil. The number of turns of the detection coil is 100 each, and the modulation coil is 153 . In order to cancel the environmental noise and to improve the spatial resolution, a gradiometric structure coil is adopted for the detection coil. This structure is similar to that which J. R. Buckley et al. used [7]. The detection coil consists of two coils, which are wound around the cylindrical YBCO cores, which are the same in size and are placed in line. The winding directions are opposite with each other. The beginning ends of the both coils are connected at the center and the winding ends are connected to the detecting amplifier, i.e. the input terminal of the lock-in amplifier. The polarity of the induced voltage due to the environmental noise magnetic flux is opposite with each other, thus the environmental noise is canceled out with this structure. The distance between the two coils is the base line length of the gradiometer, which is one of the determining factors of the spatial resolution.

\section{PERFORMANCE OF THE SENSOR}

Since a sintered $\mathrm{YBCO}$ has a granular structure, magnetic flux can penetrate through it even in the superconductive state. The detecting scheme of this superconductive fluxgate magnetic sensor is based on the nonlinearity of penetrating magnetic flux in sintered YBCO. The lock-in amplifier detects the second harmonic of the AC modulation field, which is proportional to the external magnetic field.

A characteristic of output voltage vs. modulation field is shown in Fig. 2. The output voltage increases with the

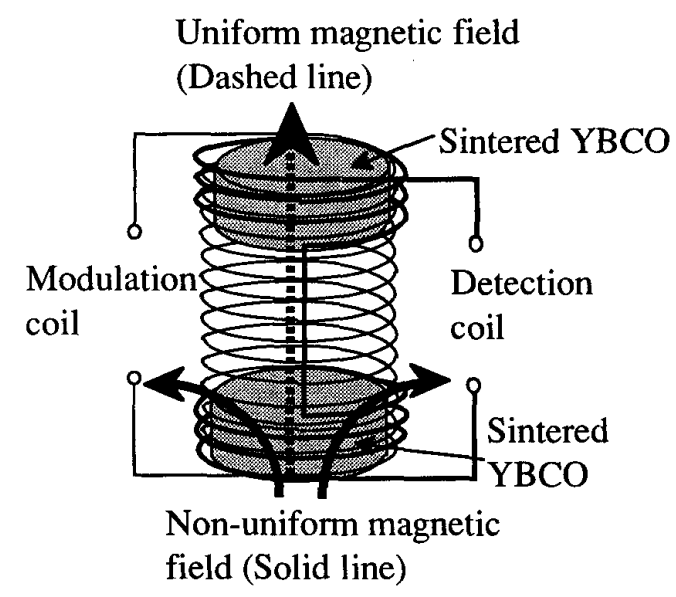

Fig. 1. Gradiometric structure of superconductive fluxgate magnetic sensor. modulation field until $700 \mathrm{~A} / \mathrm{m}$, and then starts to decrease at $700 \mathrm{~A} / \mathrm{m}$. This phenomena occurs due to trapping of magnetic flux in the sintered YBCO. It's supposed that the modulation magnetic field should be limited to under $600 \mathrm{~A} / \mathrm{m}$ to keep the sensitivity. The upper limit of the modulation frequency should be of order $\mathrm{MHz}$. We performed out an experiment at $1 \mathrm{MHz}$. However, K. Mohri et al. reported that it can be performed at more than $20 \mathrm{MHz}$ [2].

Reducing the base line length improves the spatial resolution. However, it brings a reduction of the output voltage. The base line length of $11 \mathrm{~mm}$ was adopted in this experiment because the output voltage reduces rapidly below a base line of $10 \mathrm{~mm}$ for this detection coil. Fig. 3 shows the measured result of the full width of half-maximum peak height, when the sensor detected the magnetic field generated from a small solenoid coil ( $5 \mathrm{~mm}$ length, $5 \mathrm{~mm}$ diameter) which was regarled as a source of dipole magnetic field.

The input-output transfer function of this sensor is $2.1 \times 10^{7}$ $\mathrm{V} / \mathrm{T}$. The noise level is $1.4 \mathrm{nT} / \mathrm{Hz}^{1 / 2}$. The minimum magnitude of the detectable magnetic field is approximately $3.7 \mathrm{nT}$. The whole structure is placed in a plastic dewar filled with liquid nitrogen. The thickness of the bottom of the cup restricts the shortest distance to the sample, which is $5 \mathrm{~mm}$.

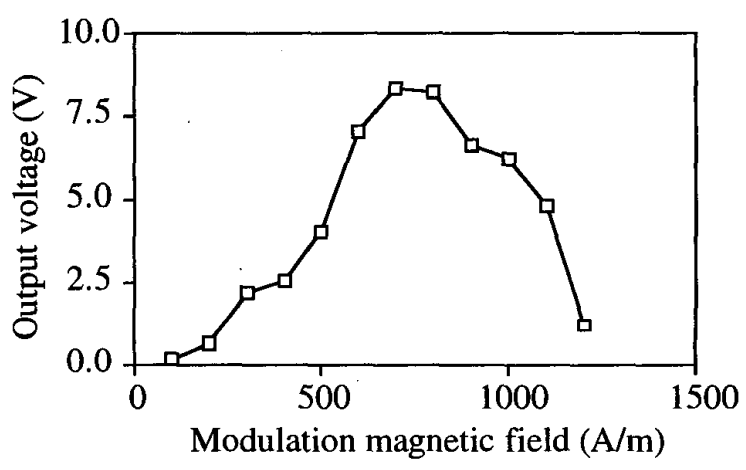

Fig. 2. Output voltage vs. modulation field characteristics.

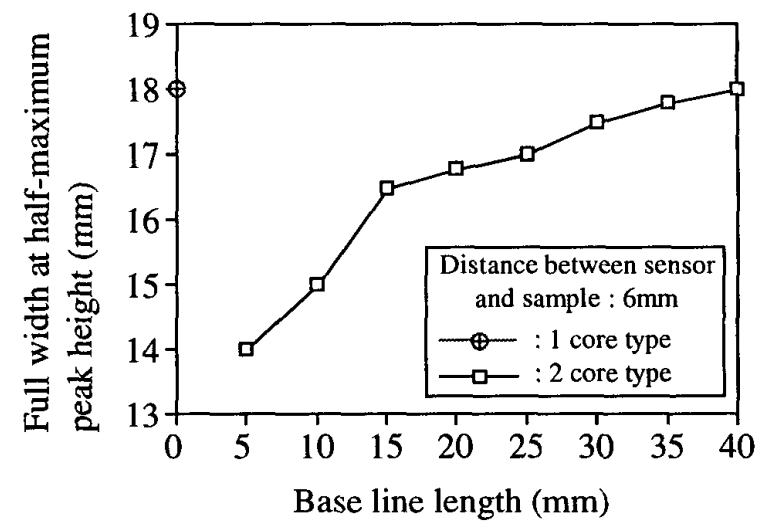

Fig. 3. Full width at half-maximum peak height vs. Base line length characteristics. 


\section{EXPERIMENTS AND DISCUSSION}

\section{A. Experimental Setup}

A magnetically quiet scanning rig was specially made for this experiment. Fig. 4 shows a schematic diagram of experimental arrangement. All the materials of the rig structure are non-magnetic and also electrically non-conductive. The $\mathrm{XY}$-axis stage was used for scanning. The moving sample plate was measured with the fixed sensor. An ac electrical current was supplied directly to the aluminum sample with a flaw. The flow lines of the current will be affected by the flaw, thus, a non-uniformity of the magnetic field due to the non-uniform flow lines of the current is expected. The distribution of the magnetic field over the flaw is detected. The clearance between the bottom end and the sample was 1 $\mathrm{mm}$, so the distance between the sensor and the sample was 6 $\mathrm{mm}$. Only the vertical component of the magnetic field from the sample is detected.

In this experiment, three sample plates shown in TABLE II were measured. Sample A has a slit of $0.2 \mathrm{~mm}$ wide and 30 $\mathrm{mm}$ long. Sample B has a slit of $10 \mathrm{~mm}$ wide and $40 \mathrm{~mm}$ long. Sample $C$ has a slit of $30 \mathrm{~mm}$ wide and $40 \mathrm{~mm}$ long. These slits lay in vertical direction which is perpendicular to the current flow direction. They are covered with another Aluminum plate which has a thickness of $1 \mathrm{~mm}$. A slit is cut at the center of rectangular aluminum plate (JIS H4000-A2017). The specific electrical conductivity is $3.64 \times 10^{-7} \mathrm{ohm}^{-1} \mathrm{~m}^{-1}$. The frequency of the applied ac current through the sample is $70 \mathrm{~Hz}$, thus the corresponding skin depth is approximately $10 \mathrm{~mm}$. The phase of the lock-in amplifier was adjusted to obtain maximum output voltage at both ends of the slit.

\section{B. Nondestructive Evaluation}

Fig 5, 6 and 7 are the measured results of the slits, over which an aluminum plate with the thickness of $1 \mathrm{~mm}$ is placed.

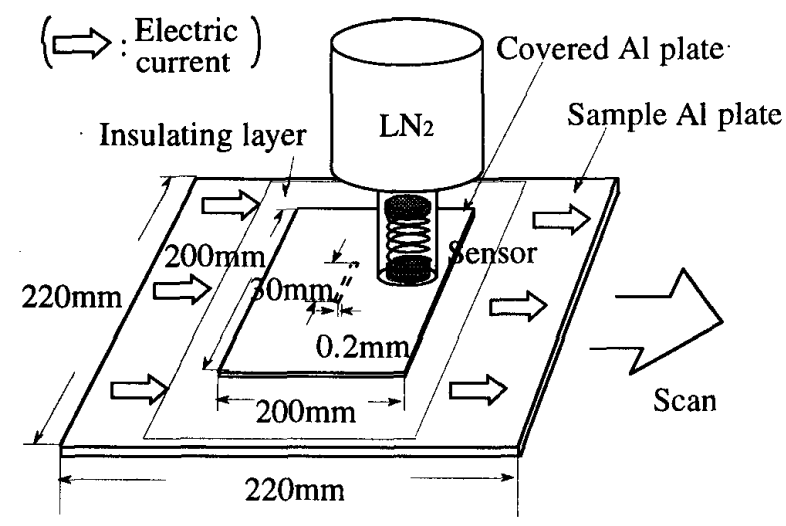

Fig. 4 A schematic diagram of experimental arrangement.
TABLE II

Numerical size of sample plates and slits.

\begin{tabular}{|c|ccc|}
\hline & sample A & sample B & sample C \\
\hline Size of sample plate & & & \\
$\left(\begin{array}{c}\text { Width } \\
\text { Length } \\
\text { Thickness }\end{array}\right)$ & $220 \mathrm{~mm}$ & $420 \mathrm{~mm}$ & $420 \mathrm{~mm}$ \\
$\cdot$ & $10 \mathrm{~mm}$ & $300 \mathrm{~mm}$ & $300 \mathrm{~mm}$ \\
Size of slit & $10 \mathrm{~mm}$ & $10 \mathrm{~mm}$ \\
$\left(\begin{array}{c}\text { Width } \\
\text { Length }\end{array}\right)$ & $0.2 \mathrm{~mm}$ & $10 \mathrm{~mm}$ & $30 \mathrm{~mm}$ \\
\end{tabular}

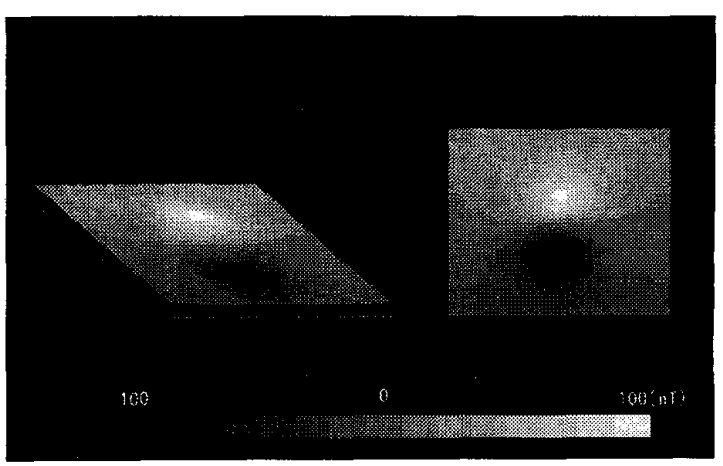

Fig. 5. Scanning result of sample A.

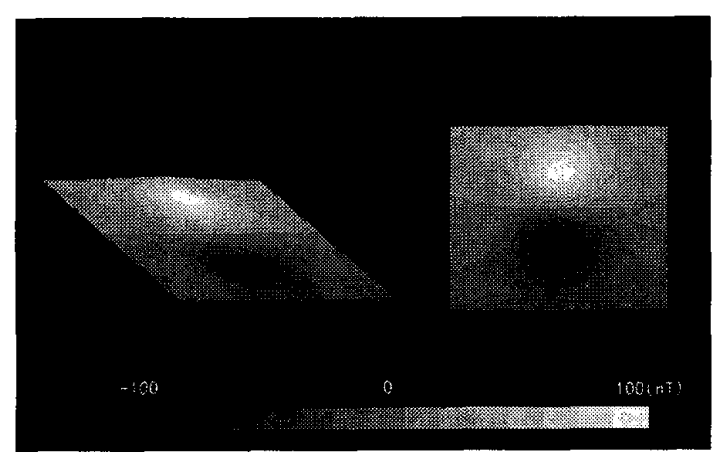

Fig. 6. Scanning result of sample B.

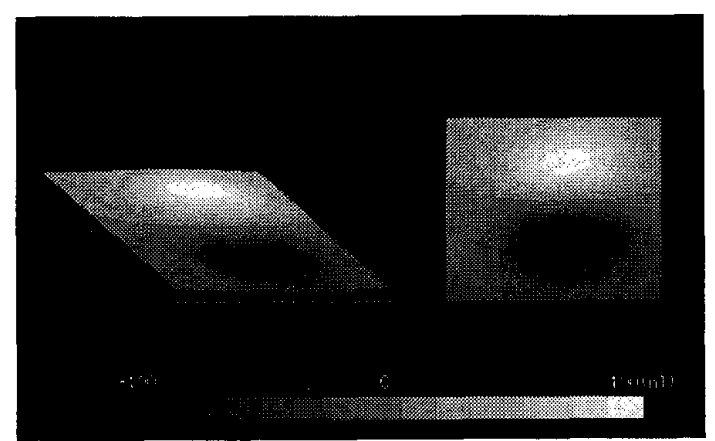

Fig. 7. Scanning result of sample C. 
There is an insulating layer of $0.08 \mathrm{~mm}$ thickness between the sample aluminum plate and the covered aluminum plate. These figures are indicated by 15 steps of the gray scale. Each scanning area is $100 \mathrm{~mm} \times 100 \mathrm{~mm}$. On the left hand side is a $3 \mathrm{D}$ bird's eye view, and on the right hand side is a $2 \mathrm{D}$ distribution. The electrical ac current in these cases is $1.0 \mathrm{~A}$. One can see the peak (bright) and the dip (dark) very clearly. The bright part indicates the positive signal, and the dark part indicates the negative signal. The centers of the peak and the dip correspond to each end of the slit.

Fig. 5 is the measured result of "sample A." This is for the case that the slit width is much smaller than the diameter of detection coil. A shape of the signal distribution is circular near the center of the peak and the dip. Fig. 6 is the measured result of "sample B." This is for the case that the slit width is approximately same as the diameter of detection coil. A shape of the signal distribution is ellipsoidal near the center of the peak and the dip. A major axis of the ellipsoid is parallel to the current direction. Fig. 7 is the measured result of "sample C." This is for the case that the slit width is much larger than the diameter of detection coil. A shape of the signal distribution shows longer ellipsoid than that of Fig. 6.

The shapes of the signal distribution depend on the slit width. The shapes of the signal distribution also should be depend on the distance between the sensor and sample. If there are the information of the distance between the sensor and sample, we could estimate the width of slit.

\section{CONCLUSION}

A fluxgate magnetic sensor with sintered YBCO cores is constructed and is applied to N.D.E. of an aluminum plate. The sensor is successfully operated in a magnetically unshielded environment. A slit ( $0.2 \mathrm{~mm}$ width, $30 \mathrm{~mm}$ long), which is considered as a flaw, on an aluminum plate is successfully detected by this sensor, even the slit is covered with another aluminum plate. The sensor can detect the flaw when as direction is perpendicular to the electric current in the sample. The distribution of the detected magnetic field became wider with increasing the width of flaw. These results suggest that the sensor has a potential for nondestructive evaluation of non-magnetic metals, such as aluminum alloys, and also for multi-layered structures, which are widely found in the fundamental structure of aircraft.

\section{ACKNOWLEDGMENT}

I would like to thank Mr. Hoshikawa and Mr. Endo for their experimental assistance.

\section{REFERENCES}

[1] J. C. Gallop, S. Lilleyman, C. D. Langham, W. J. Radcliffe, M. Stewart, "A novel HTS magnetometer, exploiting the low jc of bulk YBCO," IEEE Trans. Magn., Vol. 25, No.2, pp 896-898, 1989.

[2] K.Mohri, T.Uchiyama, A. Ozeki, "High Tc superconducting magnetic multivibrators for fluxgate magnetic-field sensors," IEEE Trans. Magn., Vol. 25, No.5, pp 3515-3517, 1989.

[3] C. Carr, D. McA. McKirdy, E. J. Romans, G. B. Donaldson, "Electromagnetic nondestructive evaluation : Moving HTS SQUIDs, Inducing field nulling and dual frequency measurements," IEEE Trans. Appl. Supercond. Vol. 7, No. 2, pp 3275-3278, 1997.

[4] Meir Gershenson, "High temperature superconductive flux gate magnetometer," IEEE Trans. Magn., Vol. 27, No.2, pp 3055-3057, 1991.

[5] H. Niculescu and P. J. Gielisse, "High temperature superconductor sensors for field magnetometry," IEEE Trans. Magn., Vol. 28, No.1, pp 809-812, 1992.

[6] M. Miyazaki, H. Nakane, H. Adachi, "The possibility of superconducting magnetometer for field work application," ISS '96, DAP-30, 1996.

[7] J. R. Buckley, Neeraj Khare, G. B. Donaldson, "Use of a bulk high Tc magnetometer for non-destructive evaluation," IEEE Trans. Magn., Vol. 27, No.2, pp 3051-3054, 1991. 